\title{
Validation of the Thomson, Perry and Miller (2007) Collaboration Instrument in the South African context
}

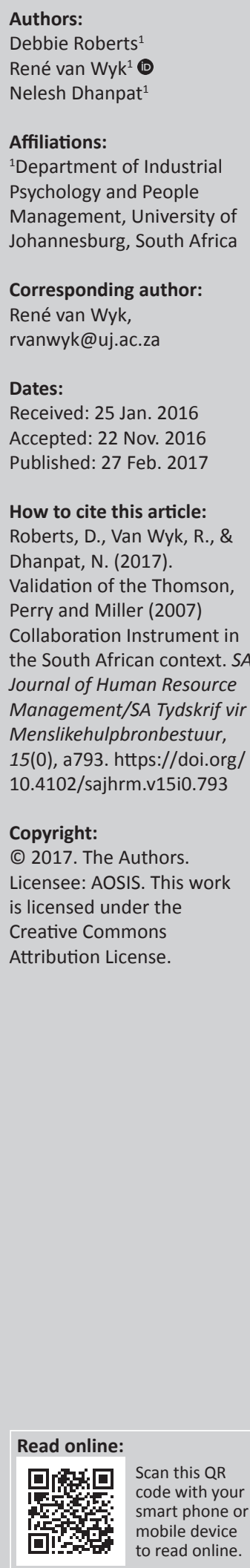

Orientation: Collaboration is deemed important in today's connected and complex business environment. People's ability to collaborate with each other in organisations is becoming a business imperative. This study focuses on a valid measurement of collaboration within organisations.

Research purpose: Thomson, Perry and Miller (2007) developed a collaboration measurement instrument in the United States. The aim of this study was to validate this instrument for a South African context.

Motivation for the study: South African organisations face unique challenges that require optimal use of resources to improve business results. Effective collaboration is considered a powerful strategy to achieve this. Measuring the extent of collaboration can help to identify required changes in business practices. As far as could be established, there is no evidence of collaboration instruments developed and validated in South Africa.

Research design, approach and method: Additional items were designed for further development of the Thomson, Perry and Miller (2007) Collaboration Instrument sub-scales, as suggested by the authors. The revised questionnaire consisting of 31 (17 existing, 14 new) items was distributed electronically to 4200 employees in two organisations, with 343 valid responses received. Reliability and construct validity were tested, as was convergent validity of the norms factor with the Trust in Teams Scale.

Main findings: The results of the study support a four-factor, 29-item model of collaboration when applied to a South African sample. Cronbach's alpha ranged between 0.85 and 0.95 . Confirmatory Factor Analysis fits were at an acceptable level. Convergent validity showed a moderate fit with the data.

Practical/managerial implications: South African managers and human resources practitioners can utilise results to foster a collaborative environment.

Contribution/value-add: This study builds on the theoretical concept of collaboration as defined by Thomson, Perry and Miller (2007).

\section{Introduction}

People's ability to collaborate with each other in organisations is becoming a business imperative. Effective collaboration can enhance product innovation and service delivery, and increase efficacy (Barber \& Goold, 2014; Miller \& Katz, 2014; Patel, Pettitt \& Wilson, 2012; Sanker, 2012; Simatupang \& Sridharan, 2005). Leveraging these benefits could be of considerable value to South African businesses. A valid measure of collaboration could help South African business leaders optimise opportunities and address obstacles to effective collaboration.

Globalisation, technology advancements and the fast rate of change are all catalysts for increased complexity in the business environment (Barber \& Goold, 2014; Kaats \& Opheij, 2014; Miller \& Katz, 2014; Sanchez, 2012). South African organisations face the same complexities as the rest of the world. The country also faces unique challenges, such as electricity shortages, labour unrest, poor quality of education and increasing debt (International Monetary Fund, 2013; World Economic Forum, 2015). Higher education enrolment rates are not foreseen to produce the level of skills required for future competitiveness (World Economic Forum, 2015). These issues place additional pressure on businesses to operate efficiently and innovatively.

Coping with this complexity requires staying abreast of new developments, solving difficult problems and at the same time seizing opportunities. This is not easy for individual entities to achieve alone (Barber \& Goold, 2014; Kaats \& Opheij, 2014; Woodland \& Hutton, 2012). 
To deal with this complexity, many organisations are moving from hierarchies to network systems. This change is necessary but can involve complicated interactions, meaning that communication, learning and innovation must be fast and effective (Kaats \& Opheij, 2014; Miller \& Katz, 2014). A powerful strategy to attain improved results under these conditions is through collaborative partnerships (Barber \& Goold, 2014; Kaats \& Opheij, 2014; Miller \& Katz, 2014; Sanchez, 2012; Thomson, Perry \& Miller, 2007; Woodland \& Hutton, 2012). This necessitates establishing an environment that fosters a collaborative culture. Further to improving business results, a collaborative culture can also improve employee morale and retention (Murphy, Arenas \& Batista, 2014). Exposure to collaboration allows individuals to perform roles other than their own, enhancing selfdevelopment (Sanchez, 2012). People also experience expanded thinking, broadened and diverse networks and inspiration from co-collaborators (Bushe, 2006). Collaboration can also provide strong social connections, which have been found to promote positive mental health (Bond, Lusher, Williams \& Butler, 2014).

Conversely, efforts to collaborate can result in failure. There are several potential obstacles to achieving a collaborative environment. Poorly designed partnership agreements usually result in ambiguous roles and the likelihood of poor communication (Patel et al., 2012). Structures, processes and technologies that do not support collaboration can create difficulties (Hudson, Hardy, Henwood \& Wistow, 1999; Kaats \& Opheij, 2014) as can weak knowledge management (Patel et al., 2012). Collaboration requires significant energy in managing varying priorities, conflicts and territory issues (Sanchez, 2012). Given these challenges, before embarking on collaboration, leaders should assess whether the reward outweighs the effort and establish that all stakeholders share this perception (Marek, Brock \& Savla, 2015; Patel et al., 2012).

Evaluation and feedback on how the organisation is progressing towards a collaborative culture is considered to be a valuable endeavour (Majchrzak, Jarvenpaa \& Bagherzadeh, 2015; Marek et al., 2015; Murphy et al., 2014; Wong, 2006). Several measurement instruments have been developed over the years, many of which apply to specific industries or disciplines. This study reviewed various collaboration instruments for their suitability for validation in a South African context and application to a general business environment. The collaboration instrument selected for this study was the Thomson, Perry and Miller (2007) Collaboration Instrument. This instrument was based upon a five-factor model of collaboration as illustrated in Figure 1.

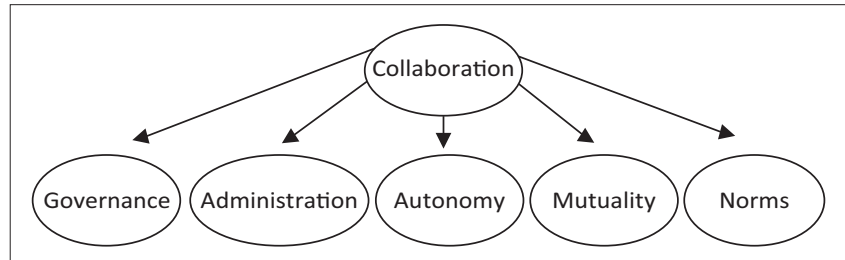

FIGURE 1: Thomson, Perry and Miller (2007) Model of Collaboration.

\section{Trends from the research literature}

Collaboration has been the focus of much scholarly research. The volume of literature suggests a keen interest in exploring this construct. Despite this interest, it is apparent that a common and accepted definition does not exist. In some cases, definitions are specific to certain environments such as education or nursing. This lack of clarity around collaboration is considered an obstacle to supporting and improving collaboration (Hudson et al., 1999; Patel et al., 2012; Thomson et al., 2007). However, there are generic definitions that support similar themes. The following operational definition, highlighting these themes, is suggested for the purpose of this study: collaboration is a combined undertaking between mutually dependent parties that have shared responsibilities on an agreed process with an envisaged outcome to deliver a result considered superior to what the parties could achieve individually (Kaats \& Opheij, 2014; Mattessich, MurrayClose \& Monsey, 2001; Sanker, 2012; Schwarz, 2006; Thomson et al., 2007). The literature discussion that follows is framed within:

- stages of collaboration

- theoretical perspectives that have contributed to collaboration

- collaboration measurement instruments.

\section{Stages of collaboration}

There is a perspective that collaboration occurs in different stages, and hence, it is a developmental process that requires reflection, review and learning (Frey, Lohmeier, Lee \& Tollefson, 2006; Gajda, 2004; Peterson, 1991). Peterson (1991) developed a three-stage model of collaboration, namely, cooperation, coordination and collaboration. The premise is that effective collaboration cannot ensue in the absence of cooperation and coordination. This implies that as the group progresses through the stages, effectiveness increases. Gajda (2004) expanded the three stages to five, identifying 'networking, cooperating, partnering, merging and unifying' (Gajda, 2004, p. 71). These are referred to as levels of integration. For each of these levels, there are descriptors under the categories of 'purpose, strategies and tasks, leadership and decision making, and interpersonal communication' (Gajda, 2004, p. 71). These stage descriptors provide a tool to identify current reality and the desired state of collaboration. They also facilitate the design of an implementation plan to work towards each stage of collaboration. Frey et al. (2006) proposed an additional stage in the collaborative process, called 'co-existence'. This is based on the premise that it is possible for a group to exist with no level of collaboration.

\section{Theoretical perspectives contributing to collaboration}

A number of organisational theories or concepts explain different facets of collaboration. Gray and Wood (1991) examined specific theories in terms of their contribution and limitations in this regard. D'Amour, Ferrada-Videla, 
San Martin Rodriguez and Beaulieu (2005) also identified particular theories that they deem as contributors to explaining collaboration. An additional concept that is considered to be linked to collaboration is social capital, which is described as the value gained through reciprocal and trusting relationships, with an important emphasis on mutually beneficial outcomes (Campbell, 2006; Ofori \& Sackey, 2010; Pastoriza, Arin \& Ricart, 2009; Wollebæk \& Selle, 2007). Most of these contributive theories provide insight into some of the reasons why individuals and organisations choose to collaborate. Elements that should be considered prior to entering into a collaboration are highlighted. They also allude to certain conditions that can enable successful collaboration. Table 1 maps these theories against (1) reasons to collaborate, (2) issues to consider prior to collaborating and (3) designing and maintaining conditions for effective collaboration.

\section{Collaboration measurement instruments}

Several collaboration measurement instruments as listed below have been developed, which were reviewed for their suitability for this study. Most of these instruments apply to specific disciplines, with few for application in a multidisciplinary context:

- Collaboration and Satisfaction about Care Decisions (Gedney Baggs, 1994): An instrument to measure nurse and doctor collaboration while making decisions on patient care.

- Collaboration and Trust in an Education Context (TschannenMoran, 2001): A measure of collaboration between principals, teachers and parents.

- Wilder Collaboration Factors Inventory (Mattessich et al., 2001): A general measure of collaboration.

- Collaboration Index: a measure for supply chain collaboration (Simatupang \& Sridharan, 2005): A scale to measure collaboration amongst participants involved in supply chains.

- Collaboration Measurement Instrument (Thomson et al., 2007): An instrument to measure collaboration in a general business context.

- Collaborative Culture Scale (Perez, Peon \& Ordas, 2011): A scale that measures the values attributed to a collaborative culture.
- Assessment of Inter-professional Team Collaboration Scale (Orchard, King, Khalili \& Bezzina, 2012): An instrument to measure collaboration between teams of health professionals.

- CoSpaces Collaborative Working Model (Patel et al., 2012): An instrument designed in the aerospace, automotive and construction industries, applicable to a general business context.

The Thomson, Perry and Miller Collaboration Instrument (Thomson et al., 2007) was selected for this study. This instrument was developed to address the lack of a common theory of collaboration, in order to inform practice. A theoretical framework was developed based on an extensive literature review and field research from which five factors were developed. Construct validity was tested on a sample in a national service program in the United States. Pre-testing of the questionnaire construction included expert reviews in five iterative stages. A seven-point Likert scale was used to explore the extent to which the participants or partner organisations engage in certain behaviours or display particular attitudes. The results indicated that Confirmatory Factor Analysis (CFA) fits at an acceptable level: root mean square error of approximation (RMSEA) 0.063, goodness of fit index (GFI) 0.97 and adjusted goodness of fit index (AGFI) 0.96 (Thomson et al., 2007). Of the 56 items tested, 17 proved to have overall and component fit. The authors present their study as a preliminary attempt to measure collaboration with scope for further research. They encourage cross-validation of their instrument on other independent samples. In contrast to other measures, the Thomson, Perry and Miller Collaboration Instrument (Thomson et al., 2007) measures collaboration in general business and not industry-specific settings. For these reasons, this instrument is considered suitable for a validation study.

\section{Problem statement and research objectives}

Because there is no evidence of an existing collaboration measure in South Africa, use of an international instrument was considered appropriate. With a limited number of tests developed specifically for South Africa, it is not unusual to make use of international instruments (Foxcroft \& Roodt, 2005; Gajda, 2004; Orchard et al., 2012). It is, however,

TABLE 1: Mapping theories of collaboration against reasons, considerations and conditions.

\begin{tabular}{|c|c|c|c|c|c|c|c|c|c|}
\hline $\begin{array}{l}\text { Reasons } \\
\text { Considerations } \\
\text { Conditions }\end{array}$ & $\begin{array}{l}\text { Resource } \\
\text { dependence }\end{array}$ & Microeconomics & $\begin{array}{l}\text { Corporate } \\
\text { social } \\
\text { performance }\end{array}$ & $\begin{array}{l}\text { Strategic } \\
\text { management }\end{array}$ & $\begin{array}{l}\text { Institutional } \\
\text { theory }\end{array}$ & Political theory & Group processes & $\begin{array}{l}\text { Social exchange } \\
\text { theory }\end{array}$ & $\begin{array}{l}\text { Social capital } \\
\text { theory }\end{array}$ \\
\hline $\begin{array}{l}\text { Reasons to } \\
\text { collaborate }\end{array}$ & $\begin{array}{l}\text { Leveraging } \\
\text { limited resources }\end{array}$ & $\begin{array}{l}\text { Improving } \\
\text { efficiencies }\end{array}$ & $\begin{array}{l}\text { Solving social } \\
\text { problems and } \\
\text { improving } \\
\text { reputation }\end{array}$ & $\begin{array}{l}\text { Reducing } \\
\text { external threats } \\
\text { or leveraging } \\
\text { opportunities }\end{array}$ & $\begin{array}{l}\text { Pressure to } \\
\text { conform }\end{array}$ & $\begin{array}{l}\text { Shared purpose } \\
\text { that protects } \\
\text { own interests }\end{array}$ & $\begin{array}{l}\text { Good } \\
\text { interpersonal } \\
\text { relationships }\end{array}$ & $\begin{array}{l}\text { Partnering with } \\
\text { a credible group }\end{array}$ & $\begin{array}{l}\text { Gaining value } \\
\text { through } \\
\text { relationships }\end{array}$ \\
\hline $\begin{array}{l}\text { Issues to } \\
\text { consider prior } \\
\text { to collaborating }\end{array}$ & $\begin{array}{l}\text { Dependency } \\
\text { levels of groups }\end{array}$ & Opportunity costs & $\begin{array}{l}\text { Reputational } \\
\text { impact }\end{array}$ & $\begin{array}{l}\text { Behaviours } \\
\text { that will result } \\
\text { in collective } \\
\text { benefit }\end{array}$ & $\begin{array}{l}\text { Current } \\
\text { institutionalised } \\
\text { behaviours and } \\
\text { processes }\end{array}$ & $\begin{array}{l}\text { Access to power } \\
\text { and resources } \\
\text { between groups }\end{array}$ & $\begin{array}{l}\text { Potential } \\
\text { territory issues } \\
\text { and conflicting } \\
\text { priorities }\end{array}$ & $\begin{array}{l}\text { Negotiation to } \\
\text { ensure equal } \\
\text { contributions }\end{array}$ & $\begin{array}{l}\text { Measurable } \\
\text { outcomes that } \\
\text { are considered } \\
\text { value adding }\end{array}$ \\
\hline $\begin{array}{l}\text { Conditions of } \\
\text { effective } \\
\text { collaboration }\end{array}$ & $\begin{array}{l}\text { Cognisance of } \\
\text { dominance } \\
\text { levels in design } \\
\text { of partnership }\end{array}$ & $\begin{array}{l}\text { Clear agreement } \\
\text { of decision- } \\
\text { making for } \\
\text { allocation of } \\
\text { resources }\end{array}$ & $\begin{array}{l}\text { Meeting the } \\
\text { needs of all } \\
\text { stakeholders }\end{array}$ & $\begin{array}{l}\text { Integration and } \\
\text { coordination of } \\
\text { functions and } \\
\text { resources }\end{array}$ & $\begin{array}{l}\text { Unlocking } \\
\text { institutional } \\
\text { barriers }\end{array}$ & $\begin{array}{l}\text { Management of } \\
\text { conflict, mutual } \\
\text { learning and } \\
\text { appropriate } \\
\text { empowerment }\end{array}$ & $\begin{array}{l}\text { Monitoring and } \\
\text { managing group } \\
\text { development } \\
\text { and dynamics }\end{array}$ & $\begin{array}{l}\text { Monitoring } \\
\text { contribution and } \\
\text { commitment of } \\
\text { parties }\end{array}$ & $\begin{array}{l}\text { Combination of } \\
\text { complementary } \\
\text { competencies }\end{array}$ \\
\hline
\end{tabular}


necessary to be cautious when using a measurement instrument originally validated in a different setting (Gregory, 2005). Certain instruments developed in other countries have been empirically tested and proved to have good portability to a South African context (Campbell \& Young, 2011; Collings, Valjee \& Penning, 2013; De Bruin, Swartz, Tomlinson, Cooper \& Molteno, 2004; Vermeulen, Schaap, Mitchell \& Kristovics, 2009). However, specific studies support the assertion that not all assessment instruments are suitable for testing in a South African environment without some adjustment (De Klerk, Boshoff \& Van Wyk, 2009; Meiring, Van de Vijver \& Rothmann, 2006; Van Eeden \& Wissing, 2008). For these reasons, it is required that instruments are appropriately tested for each setting (Donald, Thatcher \& Milner, 2014; Foxcroft \& Roodt, 2005; Gregory, 2005). This study therefore aimed to validate the Thomson, Perry and Miller Collaboration Instrument (Thomson et al., 2007) in the South African context, with the objective of using it in South African organisations. A secondary objective was to test convergent validity with the norms factor of the Thomson, Perry and Miller Collaboration Instrument (Thomson et al., 2007) with the Trust in Teams Scale (Adams, Waldherr \& Sartori, 2008).

\section{Potential value-add of the study}

This study could further the body of knowledge on collaboration through testing a conceptual model's reliability and construct validity in the South African context. Validation of the existing instrument could contribute to more reliable measures in the South African context. This may enable organisations to understand the extent to which the factors of collaboration are a strength or weakness in their organisation. Equipped with this knowledge, leaders could prioritise initiatives to create the conditions that enable improved collaboration. Human resources functions are being called upon to enhance their contribution and become strategic partners to business (Beatty, Huselid \& Schneier, 2003). An area where human resources practitioners can increase their value-add to companies is through the provision of human capital measures that support implementation of the business strategy (Beatty et al., 2003; Chrysler-Fox \& Roodt, 2014). Collaboration is an example of one such measure. This is particularly true for South Africa where human resource management has predominantly focused on industrial relations as opposed to increasing organisational effectiveness (Horwitz, 2008).

\section{Method}

\section{Research approach}

A cross-sectional quantitative design was deemed suitable for this study because a numeric description of the opinions of the participants at a specific point in time was required (Cresswell, 2014). The data were subjected to statistical analysis to test the reliability and construct validity of the Thomson, Perry and Miller Collaboration Instrument
(Thomson et al., 2007). In order to further establish the strength of the scale, it was deemed of interest to ascertain convergent validity of one of the factors with an existing valid instrument. For this purpose, the Trust in Teams Scale (Adams et al., 2008) was selected to ascertain convergent validity with the norms factor of the Thomson et al. (2007) instrument.

\section{Research design \\ Research participants}

This study was conducted in two organisations, an industrial services company and an information and communications technology company. The criterion utilised for the target population was that the respondents needed to be employees who are required to collaborate with other teams or business units. A census sampling approach was deployed, inviting all members of the target population of 4200 employees. The number of valid responses was 343 . The largest number of responses $(83.7 \%)$ was from the information and communications technology company.

The respondents' ages varied between a minimum of 20 years and a maximum of 66 years with a mean of 38 years. The majority of the respondents were men representing $61.0 \%$ of the sample. The largest group of respondents $(65.6 \%)$ possessed a grade 12 or bachelor's degree or equivalent. English speakers made up $58.5 \%$ of the sample while the second largest home language being Afrikaans at $28.7 \%$. The African languages made up $12.9 \%$ with isiZulu speakers forming the largest group (5.0\%). The number of years and months employed in the current organisation varied between a minimum of 1 month and a maximum of 29 years with a mean of 6 years and 3 months. There was a relatively even spread across respondents from various business units, with the highest group being 12\%. The largest group of respondents $(62.7 \%)$ held positions at a non-management level. Of those at a management level, $43.2 \%$ were at a middle management level. The largest group of respondents (56.3\%) were based in South Africa, Gauteng. The majority of respondents (90.9\%) were based in South Africa. The remainder (9.1\%) were from African countries, namely, Botswana, Kenya, Nigeria, United Arab Emirates, Namibia and Morocco.

\section{Measuring instruments}

The existing questionnaire devised by Thomson et al. (2007) was used for this study. The authors originally developed 56 items for their five-factor collaboration scale. These factors are governance, administration, mutuality, autonomy and norms. Items such as 'Your organisation relies on a formal agreement that spells out relationships between partner organisations' and 'Your organisation feels it's worthwhile to stay and work with partner organisations rather than leave the collaboration' were included. The items are measured on a 7-point scale, varying from 'not at all' to 'to a very great extent'. The scale was subject to validity 
studies and 17 items were retained for their statistical or theoretical relevance. Standardised lambda coefficients of 0.75 or greater were reported for 14 of the items. The CFA fits were at an acceptable level: RMSEA $0.063(p=0.01)$; RMSEA $\mathrm{Cl} 0.055-0.072$, GFI 0.97 and AGFI 0.96. The five factors were applied in this study. The original survey was designed for cross-organisational collaboration. Because this study was conducted within organisations, the word 'organisation' was replaced with 'team'.

In their recommendations for future research, Thomson et al. (2007) encouraged the addition of new items to enrich the instrument or drawing from the original 56 if deemed appropriate. In this study, 14 items were added to the scale, resulting in 31 items in total. Two items were drawn from the original 56 , because of their perceived theoretical relevance. The commitment of resources by collaborative parties is cited as a key factor in effective collaboration (Kaats \& Opheij, 2014; Mattessich et al., 2001; Patel et al., 2012). Subsequently, the item 'My team knows what resources (i.e. money, time, expertise) other teams contribute to collaborative endeavours' was re-instituted in the factor: governance. Because effective collaboration is based on the development of relationships (Frey et al., 2006; Gajda, 2004; Mattessich et al., 2001; Peterson, 1991), the item 'Developing long-term personal relationships with other teams is the most important part of collaborating' was re-instituted in the factor: norms.

The remaining 12 new items are discussed below:

- Factor: governance. "The leaders of this organisation support collaboration' supporting the theory that leaders perform a critical role in creating and maintaining a collaborative environment (Kaats \& Opheij, 2014; Patel et al., 2012).

- Factor: governance. 'Rules of engagement are agreed for all collaborative endeavours I am involved in'. The theory suggests that the dynamics of the group can make or break collaboration (Kaats \& Opheij, 2014). Hence agreeing the values, norms and communication style of the group can help to reduce anxiety (Kaats \& Opheij, 2014; Wheelan, 2005).

- Factor: governance. 'Other teams adhere to agreed rules of engagement during collaboration'. It is necessary to provide a reference for group process monitoring and feedback (Kaats \& Opheij, 2014; Wong, 2006) which the rules of engagement serve as.

- Factor: administration. 'The existing organisational structure supports collaboration between teams'. A supporting organisational design and policies and processes are cited as important structural considerations of effective collaboration (Hudson et al., 1999; Kaats \& Opheij, 2014; Patel et al., 2012). It was decided to separate policies and procedures from structure in the items, because they are different dimensions. Number 5 that follows relates to the policies and procedures item.

- Factor: administration. 'The existing organisational policies and procedures support collaboration between teams'.
- Factor: administration. 'Regular monitoring and feedback occurs between teams to establish achievement of collaborative goals'. Theoretically, the suggestion is that regular monitoring and feedback of the performance of the collaboration is critical for continuous improvement (Frey et al., 2006; Gajda, 2004; Peterson, 1991).

- Factor: autonomy. 'I can commit to collaborative endeavours, without first getting approval'. Empowerment of individuals representing their groups helps in facilitating more timeous decisions (Thomson et al., 2007). The empowerment concept was added in two items, related to the initial commitment to the collaboration and decisionmaking during the collaboration, as illustrated in the next point (8).

- Factor: autonomy. 'As team member I am aware of what decisions I am mandated to make in collaborative endeavours'.

- Factor: mutuality. 'Other teams share knowledge with my team that strengthens our operation'. The original scale contained the item 'My team shares knowledge with other teams that strengthens their operation'. This was retained, but it was considered important to include a question testing reciprocity on knowledge sharing.

- Factor: mutuality. 'The individuals in other teams put the collective interests of collaboration above their individual interests'. This concept is cited as a key success factor for successful collaboration in the literature (Hudson et al., 1999; Mattessich et al., 2001; Srivastava \& Banaji, 2011; Tsasis, 2009).

- Factor: norms. 'The people who represent other teams in collaborative endeavours are competent'. The norms factor of the scale relates to trust. Competence and consistence (see next point) are important components of trust (Adams et al., 2008; Barczak, Lassk \& Mulki, 2010; Johnson \& Grayson, 2005).

- Factor: norms. 'The people who represent other teams in collaborative endeavours are consistent'.

The Trust in Teams Scale (Adams et al., 2008) was applied to test convergent validity with the norms factor of the Thomson, Perry and Miller Collaboration Instrument (Thomson et al., 2007). The Trust in Teams Scale (Adams et al., 2008) was designed to measure four dimensions of trust, namely, competence, integrity, benevolence and predictability. The scale was originally designed for testing in a military context but the items are generic and hence applicable to any team. The questionnaire consists of 20 items with a seven-point Likert scale ranging from completely disagree to completely agree. The Trust in Teams Scale (Adams et al., 2008) performed with Cronbach's alpha ranges from 0.89 to 0.95 . CFAs confirmed the construct validity of the four-factor model, though indices were not provided by the authors (Adams et al., 2008). For the purpose of consistency with the Thomson, Perry and Miller Collaboration Instrument (Thomson et al., 2007), the scale was re-worded to 'strongly' disagree and 'strongly' agree. Because trust can be considered a socially desirable concept 
(Adams et al., 2008), it was not explicitly stated in the overview to participants as a measurement dimension.

\section{Research procedure}

The revised version of the Thomson, Perry and Miller Collaboration Instrument (Thomson et al., 2007) was distributed to a pilot group of eight professionals in organisations for feedback on face validity. They were requested to provide feedback as to whether they had any difficulties in understanding the questions and agreed with the wording and representativeness of the items on identified factors. Feedback was received from six people. Minor appropriate adjustments were made to the questionnaire and resent to this group. The second round of feedback resulted in no additional changes to the questionnaire. Two survey software programs were investigated for their suitability for data collection, namely, Survey Monkey (n.d.) and Question Pro (n.d.). The survey was loaded onto both platforms and test data were inputted. Question Pro was selected for its capability to customise, filter and export the data most efficiently. A senior member in each organisation compiled an email with a brief note encouraging staff participation in the survey. Participants were requested to respond to the questionnaire within 2 weeks. An email reminder was sent after week one.

\section{Statistical analysis}

Exploratory Factor Analysis and CFA was conducted to test for construct validity, in order to indicate how well the instrument aligns to the theoretical assumptions on collaboration. Exploratory Factor Analyses explored possible alternative factor structures with no constraints on variable loading (Blumberg, Cooper \& Schindler, 2008). This was followed by Principal Factor Analysis with Varimax Rotation. Cronbach's alpha was used to test for reliability for each of the five factors (Sekaran \& Bougie, 2013). This was to test for items that have strong relationship with each other and the relative factors of collaboration. CFA examined the fit of the adjusted theoretical model through specifying which items define each factor (Blumberg et al., 2008). The Trust in Teams Scale (Adams et al., 2008) was applied to test convergent validity with the norms factor of the Thomson, Perry and Miller Collaboration Instrument (Thomson et al., 2007).

\section{Results}

Descriptive statistics for the items in the Revised Thomson, Perry and Miller (2007) Collaboration Instrument show that all items received the minimum and maximum responses on the Likert scale. The mean ranged from 2.63 to 5.92 with standard deviations ranging from 1.220 to 1.648. All items in the Trust in Teams Scale (Adams et al., 2008) also received the minimum and maximum responses on the Likert scale. One item was removed as a duplication. The mean ranged from 4.90 to 5.89 with standard deviations ranging from 1.111 to 1.637. The mode and median indicated a high predominance of the 6 rating.
Exploratory Factor Analysis of the Revised Thomson, Perry and Miller (2007) Collaboration Instrument indicated KaiserMeyer-Olkin (KMO) measure at an acceptable level of 0.95, which is above the value (0.6) suggested by Tabachnick and Fidell (2007). The Bartlett's test of sphericity was significant at $7584.2(d f=465 ; p=0.00)$. Principal Components Analysis with Varimax rotation indicated five factors with Eigenvalues above one. The five factors explained $65.3 \%$ of the total variance.

The rotated factor matrix for the Revised Thomson, Perry and Miller (2007) Collaboration Instrument on a five-factor model resulted in only two items loading on factor five. These two items were not theoretically relevant and it was decided to delete the two items for further analyses. Governance and administration loaded on one factor, as well as two autonomy items, which was considered theoretically relevant. Rotation converged in 10 iterations. This model was further analysed by means of Principal Components Analysis with Varimax Rotation on four components. Eigenvalues above one were indicated as: Component $1=14.529$, Component $2=2.446$, Component $3=1.795$ and Component $4=1.516$. The total variance explained by the four components is $69.95 \%$, with Component 1 explaining $25.25 \%$, Component 2, 21.38\%, Component 3, 15.13\% and Component $4,8.20 \%$ of the variance in the data space. The rotated factor matrix for the Revised Thomson, Perry and Miller (2007) Collaboration Instrument on a four-factor model confirmed governance and administration as one factor. Rotation converged in eight iterations. Principal Components Analysis with Varimax Rotation of the Revised Thomson, Perry and Miller (2007) Collaboration Instrument on a four-factor model is reported in Table 2.

Exploratory Factor Analysis of the Trust in Teams Scale (Adams et al., 2008) indicated the KMO measure (KMO) above 0.6, at an acceptable level of 0.96. The Bartlett's test of sphericity was at a significant level Chi-square $=9064.85$ $(d f=171 ; p=0.000)$. Two factors with Eigenvalues were above one, explaining $78.3 \%$ of the total variance. The two components of the Trust in Teams Scale (Adams et al., 2008) were named Component 1: integrity and Component 2: competence.

Reliability of both the Revised Thomson, Perry and Miller (2007) Collaboration Instrument and the Trust in Teams Scale (Adams et al., 2008) was calculated using Cronbach's alpha coefficient. Cronbach's alpha values for the Revised Thomson, Perry and Miller (2007) Collaboration Instrument are factor 1: governance ( $\alpha=0.95)$, factor 2: mutuality ( $\alpha=0.92)$, factor 3: norms $(\alpha=0.9)$ and factor 4 : autonomy $(\alpha=0.85)$ and for the Trust in Teams Scale (Adams et al., 2008) are factor 1: integrity $(\alpha=0.97)$ and factor 2 : competence $(\alpha=0.95)$.

The CFA was done by means of EQS. The CFA of both the Revised Thomson, Perry and Miller (2007) Collaboration Instrument and the Trust in Teams Scale (Adams et al., 2008) are reported in Table 3 . Items that cross loaded and were initially omitted though did not increase fit indices. 
TABLE 2: Principal Components Analysis with Varimax Rotation of the revised Thomson, Perry and Miller (2007) Collaboration Instrument on a four-factor model.

\begin{tabular}{|c|c|c|c|c|}
\hline Items & $\begin{array}{c}\text { Factor 1: } \\
\text { Governance }\end{array}$ & $\begin{array}{l}\text { Factor 2: } \\
\text { Mutuality }\end{array}$ & $\begin{array}{l}\text { Factor 3: } \\
\text { Norms }\end{array}$ & $\begin{array}{c}\text { Factor 4: } \\
\text { Autonomy }\end{array}$ \\
\hline 1. The leaders of this organisation support collaboration. & 0.608 & 0.240 & 0.348 & -0.174 \\
\hline 2. Rules of engagement are agreed for all collaborative endeavours I am involved in. & 0.812 & 0.112 & 0.370 & -0.046 \\
\hline 3. Other teams adhere to agreed rules of engagement during collaboration. & 0.727 & 0.113 & 0.479 & -0.021 \\
\hline 4. My team knows what resources (i.e. money, time, expertise) other teams contribute to collaborative endeavours. & 0.725 & 0.330 & 0.161 & -0.009 \\
\hline 5. Other teams take my team's opinions seriously when decisions are made about collaboration-related matters. & 0.562 & 0.464 & 0.289 & -0.081 \\
\hline 6. My team brainstorms with other teams to develop solutions to mission-related problems facing collaborative endeavours. & 0.431 & 0.599 & 0.164 & -0.001 \\
\hline 7. The existing organisational structure supports collaboration between teams. & 0.729 & 0.314 & 0.312 & -0.032 \\
\hline 8. The existing organisational policies and procedures support collaboration between teams. & 0.783 & 0.203 & 0.259 & -0.035 \\
\hline 9. I understand my team's roles and responsibilities in all collaborative endeavours. & 0.604 & 0.465 & -0.001 & -0.091 \\
\hline 10. My team and other teams jointly agree about the goals of collaborative endeavours. & 0.713 & 0.472 & 0.219 & 0.027 \\
\hline 11. My team's tasks in collaborative endeavours are well coordinated with those of other teams. & 0.667 & 0.531 & 0.167 & 0.070 \\
\hline 12. Meetings with other teams accomplish what is necessary for collaboration to function well. & 0.651 & 0.470 & 0.229 & 0.027 \\
\hline 13. Regular monitoring and feedback occurs between teams to establish achievement of collaborative goals. & 0.611 & 0.506 & 0.253 & 0.022 \\
\hline 15. As team member I am aware of what decisions I am mandated to make in collaborative endeavours. & 0.552 & 0.614 & 0.012 & -0.045 \\
\hline 16. Collaboration hinders my team's ability to meet its own objectives. (R) & -0.004 & -0.007 & -0.003 & 0.866 \\
\hline 17. My team's independence is negatively affected by having to collaborate with other teams. (R) & -0.013 & 0.001 & -0.022 & 0.916 \\
\hline 18. I feel conflicted by trying to meet both the expectations of my own team and collaborative endeavours. (R) & -0.074 & 0.011 & -0.125 & 0.836 \\
\hline 19. My team, together with other teams have combined and used each other's resources so all partners benefit from collaborating. & 0.263 & 0.690 & 0.362 & -0.033 \\
\hline 20. My team shares knowledge with other teams that strengthens their operation. & 0.243 & 0.792 & 0.091 & 0.010 \\
\hline 21. Other teams share knowledge with my team that strengthens our operation. & 0.313 & 0.670 & 0.448 & 0.008 \\
\hline 22. I feel what my team brings to collaborative endeavours is appreciated by other teams. & 0.351 & 0.695 & 0.366 & -0.046 \\
\hline 23. My team achieves its own goals better by working with other teams than working alone. & 0.080 & 0.712 & 0.269 & 0.035 \\
\hline 24. My team and other teams work through differences to arrive at win-win solutions. & 0.379 & 0.660 & 0.356 & -0.054 \\
\hline 25. The individuals in other teams put the collective interests of collaboration above their individual interests. & 0.423 & 0.442 & 0.485 & 0.059 \\
\hline 26. The people who represent other teams in collaborative endeavours are trustworthy. & 0.245 & 0.318 & 0.749 & -0.113 \\
\hline 27. The people who represent other teams in collaborative endeavours are competent. & 0.164 & 0.229 & 0.833 & -0.063 \\
\hline 28. The people who represent other teams in collaborative endeavours are consistent. & 0.352 & 0.119 & 0.804 & -0.040 \\
\hline 29. My team can count on other team to meet their obligations to collaborative endeavours. & 0.272 & 0.270 & 0.760 & -0.030 \\
\hline
\end{tabular}

Source: Thomson, Perry and Miller (2007) and revised items by current authors

Factor loadings are in bold and new items are in italics.

TABLE 3: Confirmatory Factor Analysis for the revised Thomson, Perry and Miller (2007) Collaboration Instrument and the Trust in Teams Scale.

\begin{tabular}{|c|c|c|c|c|c|c|c|c|c|c|}
\hline Model & $\begin{array}{l}\text { Mardia's } \\
\text { coefficient }\end{array}$ & $\begin{array}{l}\text { Case number: } \\
\text { multivariant } \\
\text { kurtosis }\end{array}$ & $X^{2}$ & S-B $X^{2}$ & $d f$ & CFI & SRMR & RMSEA & RMSEA $90 \% \mathrm{Cl}$ & Chi-square \\
\hline \multirow[t]{5}{*}{1.1 Governance (all items) } & 37.7618 & $7(1616.3437)$ & ML 762.746 & RML (505.241) & 77 & ML 0.835 & ML 0.060 & ML 0.161 & $0.151: 0.172$ & 9.9 \\
\hline & - & 15 (1213.8172) & - & - & - & RML (0.865) & - & RML (0.128) & (0.117: 0.138) & - \\
\hline & - & 33 (1640.6477) & - & - & - & - & - & - & - & - \\
\hline & - & $146(1225.6399)$ & - & - & - & - & - & - & - & - \\
\hline & - & $312(1402.7898)$ & - & - & - & - & - & - & - & - \\
\hline \multirow{5}{*}{$\begin{array}{l}1.2 \text { Governance (omitted } \\
\text { auton14) }\end{array}$} & 33.4496 & 7 (1716.0217) & ML 682.799 & RML (446.400) & 65 & ML 0.843 & ML 0.059 & ML 0.167 & $0.155: 0.178$ & 10.5 \\
\hline & - & 15 (972.5098) & - & - & - & RML (0.873) & & RML (0.131) & (0.119: 0.142) & - \\
\hline & - & $33(842.0964)$ & - & - & - & - & - & - & - & - \\
\hline & - & $146(1295.3367)$ & - & - & - & - & - & - & - & - \\
\hline & - & $312(1519.1427)$ & - & - & - & - & - & - & - & - \\
\hline \multirow{5}{*}{$\begin{array}{l}1.3 \text { Governance (omitted } \\
\text { gov1 and admin9) }\end{array}$} & 28.88 & 7 (1239.5495) & ML 498.728 & RML (326.886) & 44 & ML 0.865 & ML 0.054 & ML 0.174 & $0.160: 0.187$ & 11.33 \\
\hline & - & 33 (922.3049) & - & - & - & RML (0.896) & - & RML (0.137) & (0.123: 0.151) & - \\
\hline & - & $50(786.2488)$ & - & - & - & - & - & - & - & - \\
\hline & - & $146(1122.9839)$ & - & - & - & - & - & - & - & - \\
\hline & - & $312(1614.8959)$ & - & - & - & - & - & - & - & - \\
\hline \multirow[t]{5}{*}{ 2. Mutuality (all items) } & 36.9255 & $14(859.7389)$ & ML 96.810 & RML (51.342) & 20 & ML 0.960 & ML 0.033 & ML 0.106 & $0.085: 0.127$ & 4.84 \\
\hline & - & 15 (919.4947) & - & - & - & RML (0.979) & - & RML (0.068) & (0.045: 0.091) & - \\
\hline & - & $223(1850.9247)$ & - & - & - & - & - & - & - & - \\
\hline & - & 239 (858.2436) & - & - & - & - & - & - & - & - \\
\hline & - & 315 (4464.1960) & - & - & - & - & - & - & - & - \\
\hline \multirow[t]{6}{*}{ 3. Norms (all items) } & 25.2232 & $1(2691.7553)$ & ML 7.203 & RML (3.977) & 2 & ML 0.994 & ML 0.014 & ML 0.087 & $0.025: 0.160$ & 3.6 \\
\hline & - & $136(730.8172)$ & - & - & - & RML (0.995) & - & RML (0.054) & (0.000: 0.132) & - \\
\hline & - & $158(556.4781)$ & - & - & - & - & - & - & - & - \\
\hline & - & 159 (618.7299) & - & - & - & - & - & - & - & - \\
\hline & - & $284(1393.9605)$ & - & - & - & - & - & - & - & - \\
\hline & - & & - & - & - & - & - & - & - & - \\
\hline
\end{tabular}


TABLE 3 (Continues...): Confirmatory Factor Analysis for the revised Thomson, Perry and Miller (2007) Collaboration Instrument and the Trust in Teams Scale.

\begin{tabular}{|c|c|c|c|c|c|c|c|c|c|c|}
\hline Model & $\begin{array}{l}\text { Mardia's } \\
\text { coefficient }\end{array}$ & $\begin{array}{l}\text { Case number: } \\
\text { multivariant } \\
\text { kurtosis }\end{array}$ & $X^{2}$ & S-B $X^{2}$ & $d f$ & CFI & SRMR & RMSEA & RMSEA $90 \% \mathrm{Cl}$ & Chi-square \\
\hline \multirow[t]{5}{*}{5.1 Integrity (all items) } & 101.5107 & $1(2528.2866)$ & ML 1015.085 & RML (434.222) & 65 & ML 0.850 & ML 0.056 & ML 0.207 & $0.195: 0.218$ & 15.62 \\
\hline & - & $15(6854.5404)$ & - & - & - & RML (0.810) & - & RML (0.129) & (0.117: 0.140) & - \\
\hline & - & $66(4669.4961)$ & - & - & - & - & - & - & - & - \\
\hline & - & $72(2501.0286)$ & - & - & - & - & - & - & - & - \\
\hline & - & $315(2085.9560)$ & - & - & - & - & - & - & - & - \\
\hline \multirow{5}{*}{$\begin{array}{l}5.2 \text { Integrity (omitted } \\
\text { tmpred12) }\end{array}$} & 102.1943 & $1(2732.1368)$ & ML 937.708 & RML (378.634) & 54 & ML 0.856 & ML 0.056 & ML 0.219 & $0.206: 0.231$ & 17.36 \\
\hline & - & $15(7355.7135)$ & - & - & - & RML (0.825) & - & RML (0.133) & (0.120: 0.145) & - \\
\hline & - & $34(1674.2971)$ & - & - & - & - & - & - & - & - \\
\hline & - & $66(4925.1388)$ & - & - & - & - & - & - & - & - \\
\hline & - & $72(2414.8816)$ & - & - & - & - & - & - & - & - \\
\hline \multirow[t]{5}{*}{ 6. Competence (all items) } & 90.536 & $11(6315.0150)$ & ML 97.998 & RML (22.361) & 9 & ML 0.973 & ML 0.031 & ML 0.144 & $0.144: 0.175$ & 10.89 \\
\hline & - & $12(12607.9881)$ & - & - & - & RML (0.978) & - & RML (0.066) & (0.032: 0.101$)$ & - \\
\hline & - & 15 (1772.4069) & - & - & - & - & - & - & - & - \\
\hline & - & $24(2159.4581)$ & - & - & - & - & - & - & - & - \\
\hline & - & $158(2040.8531)$ & - & - & - & - & - & - & - & - \\
\hline \multirow[t]{5}{*}{ Collaboration total } & 68.9059 & $1(1909.8153)$ & ML 1487.287 & RML (1022.239) & 344 & ML 0.860 & ML 0.058 & ML 0.099 & 0.093: 0.104 & 4.32 \\
\hline & - & $7(1709.8153)$ & - & - & - & RML (0.899) & - & RML (0.076) & (0.070: 0.081) & - \\
\hline & - & $15(2411.3851)$ & - & - & - & - & - & - & - & - \\
\hline & - & $312(1584.9085)$ & - & - & - & - & - & - & - & - \\
\hline & - & 315 (3957.9368) & - & - & - & - & - & - & - & - \\
\hline \multirow[t]{5}{*}{ Trust in Teams Total } & 134.379 & 11 (2592.1359) & ML 1341.656 & RML (596.134) & 134 & ML 0.868 & ML 0.072 & ML 0.162 & $0.154: 0.170$ & 10.01 \\
\hline & - & $12(5428.1333)$ & - & - & - & RML (0.834) & - & RML $(0.100)$ & (0.092: 0.109) & - \\
\hline & - & 15 (9511.8763) & - & - & - & - & - & - & - & - \\
\hline & - & $66(4740.1352)$ & - & - & - & - & - & - & - & - \\
\hline & - & $72(2585.5427)$ & - & - & - & - & - & - & - & - \\
\hline
\end{tabular}

$X^{2}$, Chi Square; S-B $X^{2}$, Satorra-Bentler (SB); $d f$, degrees of freedom; CFI, Comparative fit index; SRMR, Standardised root mean square residual; RMSEA, Root mean square error of approximation $\mathrm{Cl}$, Confidence interval; ML, Maximum likelihood? Yes maximum likelihood; RML, Robust Maximum Likelihood.

This could be due to similarity of questions. The final factors thus included the cross loading items. None of the Mardia's coefficients were less than three, which is an indication of a significant non-normality. Chi-square indices of the different factors showed a weak to good fit with the data. Weak fits are indicated in governance, integrity and competence. Collaboration total has a good fit of 4.3. Trust in Teams total has a weak fit of 10.01. Comparative fit indices are between 0.86 and 0.99 , which is between a reasonable and good fit (Hair, Black, Babin, Anderson \& Tatham, 2006). No CFA was performed on autonomy as there were only three items.

\section{Convergent validity}

Convergent validity of only the norms factor of the Revised Thomson, Perry and Miller (2007) Collaboration Instrument was tested in relation to the Trust in Teams Scale (Adams et al., 2008) by means of structural equations modelling. This is illustrated in Figure 2.

CFA of the Structural Equation Model in Figure 1 shows significant path coefficients at the $5 \%$ level of confidence. Goodness of fit indices showed a moderate fit with the data with Bentler-Bonnett normed fit index $=0.84$, comparative fit index $(\mathrm{CFI})=0.85$, Bollen's fit index $=0.85$, and RMSEA $=0.15$ within the $90 \%$ confidence interval of 0.14 and 0.15 .

\section{Discussion}

The results of this study provide acceptable indices of the Revised Thomson, Perry and Miller (2007) Collaboration

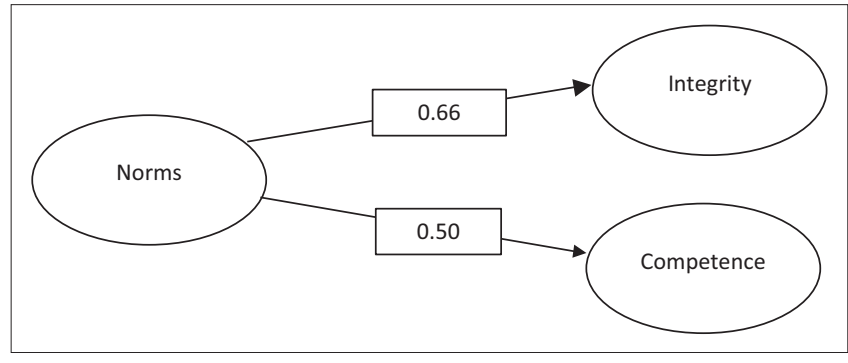

FIGURE 2: Structural equation model of the prediction of Trust in Teams Scale (Adams et al., 2008) by means of the norms factor of the Revised Thomson, Perry and Miller (2007) Collaboration Instrument.

Instrument when applied to a South African sample. It affirms the premise by Foxcroft and Roodt (2005) that instruments used in alternative countries must be validated for a South African context. It addresses the recommendations of Thomson et al. (2007) to refine their scale with the addition of items and subsequent testing of construct validity in other contexts.

Thirteen of the fourteen new items were retained. Only two items in total were eliminated, both which loaded on factor five in the initial Principal Components Analysis. These items were eliminated as they could not be theoretically explained. The moderate convergent validity with the prediction of norms on the trust factors of integrity and competence could be due to the different reference to team collaboration of the two instruments. The Revised Thomson, Perry and Miller (2007) Collaboration Instrument refers to participants' experience of individuals in other teams, for example, 'The people who represent other teams in collaborative endeavours 
are competent'. The Trust in in Teams Scale (Adams et al., 2008) makes reference to participants' experience of own teammates, for example, 'My teammates are capable at their jobs'.

\section{Linking findings to the literature}

Thomson et al. (2007) defined five factors of collaboration, namely, governance, administration, mutuality, autonomy and norms. In this study, governance and administration loaded on one factor; hence, the results support a reliable four-factor model of collaboration. The high inter-correlation between these factors is an indication that items are too similar. This is an indication that future research should phrase items for these factors to create a clearer distinction. Thomson et al. (2007) made the following distinction between governance and administration: Governance is based on the creation of rules and structures around decisions for the collaboration, and administration focuses on implementation and management. The administration items of the Revised Thomson, Perry and Miller (2007) Collaboration Instrument reference the existence of supporting structures, policies, clarity of roles, goals and tasks and the existence of meetings and monitoring mechanisms. As far as could be ascertained from existing literature, the essence of governance and administration is not categorised as distinctly as the Thomson et al. (2007) model (Kaats \& Opheij, 2014; Mattessich et al., 2001; Oziewicz, 2007; Patel et al., 2012). Theoretically, these components could be considered part of governance and hence in this study were interpreted as one factor.

The four-factor model is well supported by the literature. The factor of governance (including administration) measures the creation and implementation of rules and structures that govern the collaboration. This supports the assertion that establishing structural processes, work standards, methods and frameworks to guide collaborative relationships is important (Campbell, 2006; Kaats \& Opheij, 2014; Patel et al., 2012; Sanchez, 2012; Thomson et al., 2007). This factor also encompasses the notion that clear goals, roles, policy guidelines and communication channels are important components in collaboration as identified by various authors (Kaats \& Opheij, 2014; Mattessich et al., 2001; Patel et al., 2012; Petri, 2010; Quicke, 2000; Sanchez, 2012).

The factor of mutuality is supported by the concept that mutual dependence provides the most suitable conditions for collaboration (Henneman, Lee \& Cohen, 1995; Petri, 2010). Furthermore, perceived mutually beneficial outcomes are cited as important in collaborative endeavours (Campbell, 2006; Ofori \& Sackey, 2010; Pastoriza, Arin \& Ricart, 2009; Wollebæk \& Selle, 2007). Managing conflict is a component of the mutuality factor which is supported by Gajda (2004) who proposed that conflict can even be constructive, however proper management thereof is important.

The factor of norms is underpinned by the perceptions of individuals that collaborative partners can be trusted.
This supports the assertion that trust plays a key role in collaborative relationships (Kaats \& Opheij, 2014; Mattessich et al., 2001; Patel et al., 2012; Thomson et al., 2007). Both affective and cognitive trust elements (Johnson \& Grayson, 2005) are represented in the items. Cognitive trust relates to the perception that the other party is capable and likely to deliver on their commitments. Affective trust is based on positive relational experiences.

The factor of autonomy refers to the tension between the collective interests of all parties and the self-interest of groups (Thomson et al., 2007). Hudson et al. (1999) supported the existence of this tension through encouraging collaborative parties to recognise where interdependence is appropriate and respect where independence is warranted. Tsasis (2009) also proposed that a balance between autonomy and dependence is required for effective collaboration.

\section{Implications for practice}

The Revised Thomson, Perry and Miller (2007) Collaboration Instrument provides a measure for leaders and HR practitioners to explore the status of collaboration in organisations and across organisations in South Africa. The results could provide HR practitioners information that helps them to identify opportunities for leadership development, knowledge sharing, inter-team effectiveness and bottom-up collaboration. This could help to promote the positioning of the human resource function as a strategic business partner. The theoretical model alone can be used by organisations as a conversational framework to explore perceptions on collaboration in different contexts. The results of a collaboration assessment could suggest courses of action for leaders to address obstacles and challenges associated with collaboration such as varying priorities, conflicts and territory issues (Sanchez, 2012) and create mechanisms to mitigate these. This should enable organisations to leverage the benefits of effective collaboration.

\section{Limitations of the study and implications for future research}

Although the study shows the four-factor Revised Thomson et al. (2007) to be valid for a South African sample, various limitations should be considered. This study was done only in two organisations in South Africa, in two industries, information technology and industrial services. A larger variety of organisations and other countries should be considered in future research. The sample obtained was predominantly English and Afrikaans speaking (87.5\%), with a small percentage representing the remaining nine official languages of South Africa. Future studies should aim to acquire a more South African demographically representative sample.

Cross-loadings of items indicate a lack of variety between questions, especially in the case of governance and administration. Future measure of this instrument should 
phrase items to show more variety between questions. Specifically, the governance and administration items should be phrased in a manner that would make a clearer distinction between these two factors.

Future studies on convergent validity of the norms factor of the Thomson, Perry and Miller Collaboration Instrument (Thomson et al., 2007) and trust instruments should phrase participants' team experience and observation in a similar fashion to address the moderate results of the convergent validity.

This study has only examined the validity of one instrument in a South African context. Subsequent to completion of this research, an article by Marek et al. (2015) was published. The authors developed and validated a Collaboration Assessment Tool for use in a general business context. Internal consistency of the instrument was 0.97. CFA fits were at an acceptable level: $\mathrm{RMSEA}=0.06$. It is evident that this instrument would have also been suitable for validation for the South African context had it been published prior to the planning of this study. Future research could therefore focus on validation of other appropriate instruments for South Africa.

A beneficial future research focus would be to conduct longitudinal studies to explore the impact of time and other contextual changes on collaboration processes. Longitudinal studies could also further test the premise that collaboration occurs in a series of stages (Frey et al., 2006; Gajda, 2004; Peterson, 1991).

\section{Conclusion}

This research demonstrated the importance of collaboration between and within organisations. South African businesses face many external and internal challenges that necessitate the optimal use of resources for increased efficiency and innovation. It is evident that this can be achieved through collaborative partnerships. If South African leaders are to leverage the benefits of their workforce through collaboration, they require insight into the status of collaboration in order to initiate change. As far as could be ascertained, there is no evidence of a measurement instrument to provide this insight in South Africa. Organisations place themselves at risk when using an instrument developed in another country and not tested for use with their specific population. The Revised Thomson, Perry and Miller Collaboration Instrument addresses the need for a collaboration instrument validated for a South African sample. In conclusion, this study contributes to the understanding of collaboration and how to maximise its practical benefits.

\section{Acknowledgements Competing interests}

The authors declare that they have no financial or personal relationships that may have inappropriately influenced them in writing this article.

\section{Authors' contributions}

D.R. was responsible for the project design, R.v.W. and N.D. were the project leaders and made conceptual contributions.

\section{References}

Adams, B.D., Waldherr, S., \& Sartori, J. (2008). Trust in teams scale trust in leaders scale manual for administration and analyses. Toronto, ON: HumanSystems Inc.

Barber, F., \& Goold, M. (2014). Collaboration strategy - How to get what you want from employees, suppliers and business partners. London, UK: Bloomsbury.

Barczak, G., Lassk, F., \& Mulki, J. (2010). Antecedents of team creativity: An examination of team emotional intelligence, team trust and collaborative culture.
Creativity and Innovation Management, 19(4), 332-345. https://doi.org/10.1111/ j.1467-8691.2010.00574.x

Beatty, R.W., Huselid, M.A., \& Schneier, C.E. (2003). New HR metrics: Scoring on the business scorecard. Organizational Dynamics, 32(2), 107-121. https://doi. org/10.1016/S0090-2616(03)00013-5

Blumberg, B., Cooper, D.R., \& Schindler, P.S. (2008). Business research methods (3rd edn.). Berkshire, UK: McGraw-Hill.

Bond, L., Lusher, D., Williams, I., \& Butler, H. (2014). Friends or foes? Relational dissonance and adolescent psychological wellbeing. PLoS One, 9(2), 1-10. https:// doi.org/10.1371/journal.pone.0083388

Bushe, G.R. (2006). Sense making and the problems of learning from experience: Barriers and requirements for creating cultures of collaboration. In S. Schuman (Ed.), Creating a culture of collaboration (pp. 151-171). San Francisco, CA: JosseyBass.

Campbell, J.M. (2006). Renewing social capital. In S. Schuman (Ed.), Creating a culture of collaboration (p. 41-55). San Francisco, CA: Jossey-Bass.

Campbell, M., \& Young, C. (2011). Introducing the CORE-OM in a South African context: Validation of the CORE-OM using a South African student population sample. South African Journal of Psychology, 41(4), 488-502. https://doi. org/10.1177/008124631104100408

Chrysler-Fox, P.D., \& Roodt, G. (2014). Changing domains in human capital measurement. SA Journal of Human Resource Management, 12(1), 1-12. https:// doi.org/10.4102/sajhrm.v12i1.585

Collings, S.J., Valjee, S.R., \& Penning, S.L. (2013). Development and preliminary validation of a screen for interpersonal childhood trauma experiences among school-going youth in Durban, South Africa. Journal of Child and Adolescent Mental Health, 25(1), 23-34. https://doi.org/10.2989/17280583.2012.722552

Cresswell, J.W. (2014). Research design: Qualitative, quantitative \& mixed methods approaches (4th edn.). London, UK: Sage.

D’Amour, D., Ferrada-Videla, M., San Martin Rodriguez, L., \& Beaulieu, M.D. (2005). The conceptual basis for interprofessional collaboration: Core concepts and theoretical frameworks. Journal of Interprofessional Care, 19(Suppl 1), 116-131. https://doi.org/10.1080/13561820500082529

De Bruin, G.P., Swartz, L., Tomlinson, M., Cooper, P.J., \& Molteno, C. (2004). The factor structure of the Edinburgh postnatal depression scale in a South African periurban settlement. South African Journal of Psychology, 34(1), 113-121. https:// doi.org/10.1177/008124630403400107

De Klerk, J.J., Boshoff, A.B., \& Van Wyk, R. (2009). Measuring meaning in life in South Africa: Validation of an instrument developed in the USA. South African Journa of Psychology, 39(3), 314-325. https://doi.org/10.1177/008124630903900306

Donald, F., Thatcher, A., \& Milner, K. (2014). Psychological assessment for redress in South African organisations: Is it just? South African Journal of Psychology, 44(3), 333-350. https://doi.org/10.1177/0081246314535685

Foxcroft, C., \& Roodt, G. (2005). An introduction to psychological assessment in the South African context (2nd edn.). Cape Town, South Africa: Oxford University Press.

Frey, B.B., Lohmeier, J.H., Lee, S.W., \& Tollefson, N. (2006). Measuring collaboration among grant partners. American Journal of Evaluation, 27(3), 383-392. https:// doi.org/10.1177/1098214006290356

Gajda, R. (2004). Utilizing collaboration theory to evaluate strategic alliances. American Journal of Evaluation, 25(1), 65-77. https://doi.org/10.1177/ 109821400402500105

Gedney Baggs, J. (1994). Development of an instrument to measure collaboration and satisfaction about care decisions. Journal of Advanced Nursing, 20, 176-182. https://doi.org/10.1046/j.1365-2648.1994.20010176.x

Gray, B., \& Wood, D.J. (1991). Collaborative alliances: Moving from practice to theory. Journal of Applied Behavioural Science, 27(2), 3-22. https://doi.org/0803973233

Gregory, R.J. (2005). The history of psychological testing. In S. Frail (Ed.), Psychological testing: History, principles and applications (5th edn., pp. 45-75). Boston, MA Pearson.

Hair, J.F., Jr., Black, W.C., Babin, B.J., Anderson, R.E., \& Tatham, R.L. (2006). Multivariate data analysis. Upper Saddle River, NJ: Pearson.

Henneman, E., Lee, J., \& Cohen, J. (1995). Collaboration: A concept analysis. Journal of Advanced Nursing, 21, 103-109. https://doi.org/10.1046/j.1365-2648.1995. 21010103.x

Horwitz, F. (2008). Key issues facing human resource management. Leader. Retrieved July 31, 2015, from http://www.leader.co.za/article.aspx?s=1\&f=1\&a=393 
Hudson, B., Hardy, B., Henwood, M., \& Wistow, G. (1999). In Pursuit of inter-agency collaboration in the public sector. Public Management Review, 1(2), 37-41. collaboration in the public sector. Public
https://doi.org/10.1080/14719039900000005

Human Resource Development Strategy for South Africa 2010-2030. (2009). Retrieved July 31, 2015, from http://www.gov.za

International Monetary Fund. (2013). South Africa: IMF Country report. Washington, DC: International Monetary Fund.

Johnson, D., \& Grayson, K. (2005). Cognitive and affective trust in service relationships. Journal of Business Research, 58(4), 500-507. https://doi.org/10.1016/S0148 2963(03)00140-1

Kaats, E., \& Opheij, W. (2014). Creating conditions for promising collaboration London: Springer.

Majchrzak, A., Jarvenpaa, S.L., \& Bagherzadeh, M. (2015). A review of interorganizational collaboration dynamics. Journal of Management, 41(5), 1338-1360. https://doi.org/10.1177/0149206314563399

Marek, L.I., Brock, D.-J.P., \& Savla, J. (2015). Evaluating collaboration for effectiveness: Conceptualization and measurement. American Journal of Evaluation, 36(1), 67-85. https://doi.org/10.1177/1098214014531068

Mattessich, P.W., Murray-Close, M., \& Monsey, B.R. (2001). Collaboration: What makes it work. V. Hyman (Ed.) (2nd edn.). Saint Paul, MN: Fieldstone Alliance.

Meiring, D., Van de Vijver, F.J.R., \& Rothmann, S. (2006). Bias in an adapted version of the 15FQ+in South Africa. South African Journal of Psychology, 36(2), 340-356. https://doi.org/10.1177/008124630603600208

Miller, B.F.A., \& Katz, J.H. (2014). 4 keys to accelerating collaboration. OD Practitioner, 46(1), 6-12.

Murphy, M., Arenas, D., \& Batista, J.M. (2014). Value creation in cross-sector collaborations: The roles of experience and alignment. Journal of Business Ethics, 130, 145-162. https://doi.org/10.1007/s10551-014-2204-x

Ofori, D., \& Sackey, J. (2010). Assessing social capital for organisational performance: Initial exploratory insights from Ghana. Organizations and Markets in Emerging Economies, 1(2), 71-91.

Orchard, C.A., King, G.A., Khalili, H., \& Bezzina, M.B. (2012). Assessment of interprofessional team collaboration scale (AITCS): Development and testing. Journal of Continuing Education in the Health Professions, 32(1), 58-67. https:// doi.org/10.1002/chp

Oziewicz, M. (2007). Joseph Campbell's 'New Mythology' and the rise of mythopoeic fantasy. The AnaChronist, 13, 114-130.

Pastoriza, D., Arin, M.A., \& Ricart, J.E. (2009). Creating an ethical work context: A pathway to generate social capital in the firm. Journal of Business Ethics, 88 477-489. https://doi.org/10.1007/s10551-009-0121-1

Patel, H., Pettitt, M., \& Wilson, J.R. (2012). Factors of collaborative working: A framework for a collaboration model. Applied Ergonomics, 43(1), 1-26. https:// doi.org/10.1016/j.apergo.2011.04.009

Perez, S., Peon, J., \& Ordas, C. (2011). Managing knowledge: The link between culture and organizational learning. Journal of Knowledge Management, 8(6), 93-104. https://doi.org/10.1108/13673270410567657

Peterson, N.L. (1991). Interagency collaboration under part H: The key to comprehensive, multidisciplinary, coordinated infant/toddler intervention services. Journal of Early Intervention, 15(1), 89-105. https://doi.org/10.1177/ services. Journal of Early
105381519101500111

Petri, L. (2010). Concept analysis of interdisciplinary collaboration. Nursing Forum 45(2), 73-82. https://doi.org/10.1111/j.1744-6198.2010.00167.x

Question Pro. (n.d.). Retrieved August 29, 2015, from http://www.questionpro.com/
Quicke, J. (2000). A new professionalism for a collaborative culture of organizational learning in contemporary society. Educational Management Administration \& Leadership, 28(3), 299-315. https://doi.org/10.1177/0263211X000283005

Sanchez, M. (2012). A collaborative culture. OD Practitioner, 44(2), 7-12.

Sanker, D. (2012). Collaborate: The art of we. San Francisco, CA: Jossey-Bass.

Schwarz, R. (2006). Using the facilitative leader approach to create an organizational culture of collaboration. In S. Schuman (Ed.), Creating a culture of collaboration (pp. 281-301). San Francisco, CA: Jossey-Bass.

Sekaran, U., \& Bougie, R. (2013). Research methods for business: A skill-building approach (6th edn.). West Sussex: Wiley.

Simatupang, T.M., \& Sridharan, R. (2005). The collaboration index: A measure for supply chain collaboration. International Journal of Physical Distribution \& Logistics Management, 35(1), 44-62. https://doi.org/10.1108/09600030510 577421

Srivastava, S.B., \& Banaji, M.R. (2011). Culture, cognition, and collaborative networks in organizations. American Sociological Review, 76(2), 207-233. https://doi. org $/ 10.1177 / 0003122411399390$

Survey Monkey (n.d.). Retrieved August 29, 2015, from https://www.surveymonkey.com/

Tabachnick, B.G., \& Fidell, L.S. (2007). Using multivariate statistics. Yuba County, CA: Pearson.

Thomson, A.M., Perry, J., \& Miller, T. (2007). Conceptualizing and measuring collaboration. Journal of Public Administration Research and Theory, 19(1), 23-56. https://doi.org/10.1093/jopart/mum036

Thomson, A.M., Perry, J., \& Miller, T. (2008). Linking collaboration processes and outcomes foundations for advancing empirical theory. In R. O'Leary \& L. Bingham (Eds.), Collaborative public management: The big questions (pp. 97-120). New York: Sharpe.

Tsasis, P. (2009). The social processes of interorganizational collaboration and conflict in nonprofit organizations. Nonprofit Management and Leadership, 20(1), 5-21. https://doi.org/10.1002/nml.238

Tschannen-Moran, M. (2001). Collaboration and the need for trust. Journal of Educational Administration, 39(4), 308-331. https://doi.org/10.1108/ EUM0000000005493

Van Eeden, C., \& Wissing, M.P. (2008). Karaktersterktes herontdek in die sielkunde. Tydskrif Vir Geesteswetenskappe, 48(1), 78-95.

Vermeulen, L.P., Schaap, P., Mitchell, J.I., \& Kristovics, A. (2009). Exploring the equivalence of the aviation gender attitude questionnaire for South African and Australian pilots: A cross-cultural comparison. The International Journal of Aviation Psychology, 19(4), 367-390. https://doi.org/10.1080/1050841090 3187604

Wheelan, S.A. (2005). Group processes - A developmental perspective (2nd edn.) Boston, MA: Pearson.

Wollebæk, D., \& Selle, P. (2007). Origins of social capital: Socialization and institutionalization approaches compared. Journal of Civil Society, 3(1), 1-24. https://doi.org/10.1080/17448680701390638

Wong, P.T.P. (2006). Is your organization an obstacle course or a relay team: A meaning-centred approach to creating a collaborative culture. In S. Schuman (Ed.), Creating a culture of collaboration (pp. 229-256). San Francisco, CA: Jossey(Ed.),
Bass.

Woodland, R.H., \& Hutton, M.S. (2012). Evaluating organizational collaborations: Suggested entry points and strategies. American Journal of Evaluation, 33(3), 366-383. https://doi.org/10.1177/1098214012440028

World Economic Forum. (2015). The global competitiveness report 2015-2016 (Vol.5). Geneva: World Economic Forum. 